\title{
Histochemically demonstrable fibre abnormalities in normal skeletal muscle and in muscle from carriers of Duchenne muscular dystrophy
}

\author{
C. J. MORRIS AND J.A. RAYBOULD \\ From the Woolf Neuropathology Laboratory, Midland Centre for Neurosurgery and Neurology, \\ Warley, Worcestershire
}

SUMMARY Deltoid muscle was removed at motor point biopsy from 10 female relatives of patient» with Duchenne muscular dystrophy and from seven others, with no evidence of neuromuscular disease. Transverse cryostat sections of the muscle from each case were stained for reduced di $\cong$ phosphopyridine nucleotide diaphorase and it was found that all contained varying numbers ot degenerating type 1 fibres. The percentage of abnormal fibres in the type 1 fibre population was then? calculated for each case and it was found that the muscles from the patients with dystrophic relatives contained considerably higher percentages of abnormal fibres, which also showed more severew degeneration, than did the muscles from the normal cases. There was no absolute correlatiळn between serum creatine kinase levels and degree of pathological change, though patients with most severe changes in their muscles had abnormally high serum creatine kinase levels. It is suggeste.e that histochemical studies could be a useful addition to the present diagnostic tests for the carreep state in Duchenne muscular dystrophy.

The occurrence of focal histological abnormalities in the muscle of carriers of Duchenne muscular dystrophy has been well documented (Dubowitz, 1963a; Emery, 1963, 1965a, b; Stephens and Lewin, 1965; Pearce, Pearce, and Walton, 1966; Radu, Migea, Török, Bordeianu, and Radu, 1968; Ionasescu, Vuia, Luca, and Popa, 1969) such abnormalities also occurring in normal muscle (Adams, 1968). Histochemical investigations have also revealed occasional abnormal fibres in the muscle of some carriers (Engel and Cunningham, 1970; Roy and Dubowitz, 1970) and it is likely that such abnormal fibres also occur in normal muscle. A histochemical comparison of normal and carrier muscle fibres may, therefore, be of use in deciding the significance and possible diagnostic importance of the observed abnormalities.

\section{METHODS}

Motor point biopsies (Coërs and Woolf, 1959) were performed under local (cases 1-11, 16, and 17) or general anaesthetic (cases 12-15) on the deltoid muscle of 11 females with a family history of Duchenne muscular dystrophy. Of these six were possible carriers, two w probable carriers, and three definite carriers (Pearce Pennington, and Walton, 1964; Thompson, Murphy and McAlpine, 1967). Deltoid muscle was removed ir the same way from six volunteer male patients, foup undergoing orthopaedic operations (cases 12-15) andD two husbands of dystrophic carriers (cases 16 and $17 \mathcal{P}^{2}$ (Table).

Several small pieces of muscle cut at random from each biopsy were rapidly frozen in liquid nitrogen and subsequently stored in small polyethylene containers inp. the deep freeze. Transverse sections of the muscle were cut at $6 \mu \mathrm{m}$ on a cryostat with a cabinet temperature of $-20^{\circ} \mathrm{C}$ and were attached directly to alcohol cleane microscope slides. The sections were allowed to drys briefly at room temperature and were then stained fo reduced diphosphopyridine nucleotide diaphorase (DPNH-D) (Scarpelli, Hess, and Pearse, 1958). The sections were fixed in $4 \%$ formaldehyde in normal salineo overnight, treated with acetone to remove mono formazan, washed in distilled water, and mounted iro polyvinylpyrrolidone (Burstone, 1957). The percentageof abnormal type 1 fibres was calculated from a randomf examination of 300 type 1 fibres from each case.

Creatine kinase levels in venous blood taken at rest $N$ were estimated by the method of Hughes (Hughes, 1962) modified for the autoanalyser (Siegel and Cohen, 1966)우 
TABLE

SUMMARY OF RESULTS FROM MUSCLE ENZYME HISTOCHEMISTRY AND CREATINE KINASE ESTIMATIONS

\begin{tabular}{rrlcr}
\hline Case no. & $\begin{array}{c}\text { Age } \\
(y r)\end{array}$ & $\begin{array}{c}\text { Genetic } \\
\text { carrier status }\end{array}$ & $\begin{array}{c}\text { Creatine } \\
\text { phosphokinase } \\
(\text { i.u./l.*) }\end{array}$ & $\begin{array}{c}\% \text { Abnormal } \\
\text { type I fibres }\end{array}$ \\
\hline 1 & 31 & Possible & $123 \cdot 0$ & $8 \cdot 2$ \\
2 & 46 & Definite & $259 \cdot 0$ & $6 \cdot 5$ \\
3 & 37 & Definite & $390 \cdot 0$ & $9 \cdot 1$ \\
4 & 24 & Possible & $26 \cdot 1$ & $15 \cdot 7$ \\
5 & 47 & Definite & $97 \cdot 7$ & $6 \cdot 7$ \\
6 & 32 & Probable & $35 \cdot 1$ & $4 \cdot 1$ \\
7 & 22 & Possible & $32 \cdot 3$ & $13 \cdot 5$ \\
8 & 36 & Possible & $250 \cdot 0$ & $2 \cdot 7$ \\
9 & 18 & Possible & $38 \cdot 2$ & $0 \cdot 7$ \\
10 & 38 & Probable & $24 \cdot 6$ & $4 \cdot 7$ \\
11 & 33 & Possible & - & $5 \cdot 4$ \\
12 & 42 & Normal & - & $0 \cdot 7$ \\
13 & 21 & Normal & - & $0 \cdot 4$ \\
14 & 12 & Normal & $32 \cdot 9$ & $0 \cdot 0$ \\
15 & 15 & Normal & - & $0 \cdot 2$ \\
16 & 34 & Normal & - & $1 \cdot 2$ \\
17 & 36 & Normal & - & $0 \cdot 9$ \\
\hline
\end{tabular}

*Normal values: females $<60$ i.u./l., males $<80$ i.u./l.

\section{RESULTS}

The muscle from all the cases studied showed well defined normal differentiation into types 1,2 , and intermediate fibres, the three being present in a normal random mozaic. In all cases, the great majority of the type 2 and intermediate fibres were of normal size and structure, though a few showed slight intermyofibrillar network disruption of doubtful significance. The type 1 fibres were affected to different degrees in the various cases, there being no abnormal fibres in case 14 but $15.7 \%$ in case 4 (Fig. 1). Cases 1-8, 10, and 11 had higher percentages of abnormal fibres $(2.7$ to $15.7 \%)$ than did the other seven cases ( 0 to $1 \cdot 2 \%$ ). The structure of the abnormal type 1 fibres varied between two extremes:

1. Somewhat atrophic angular fibres with coarse and fragmented intermyofibrillar networks and well marked subsarcolemmal enzyme activity around the whole fibre periphery (Figs. 2, 3, 4).

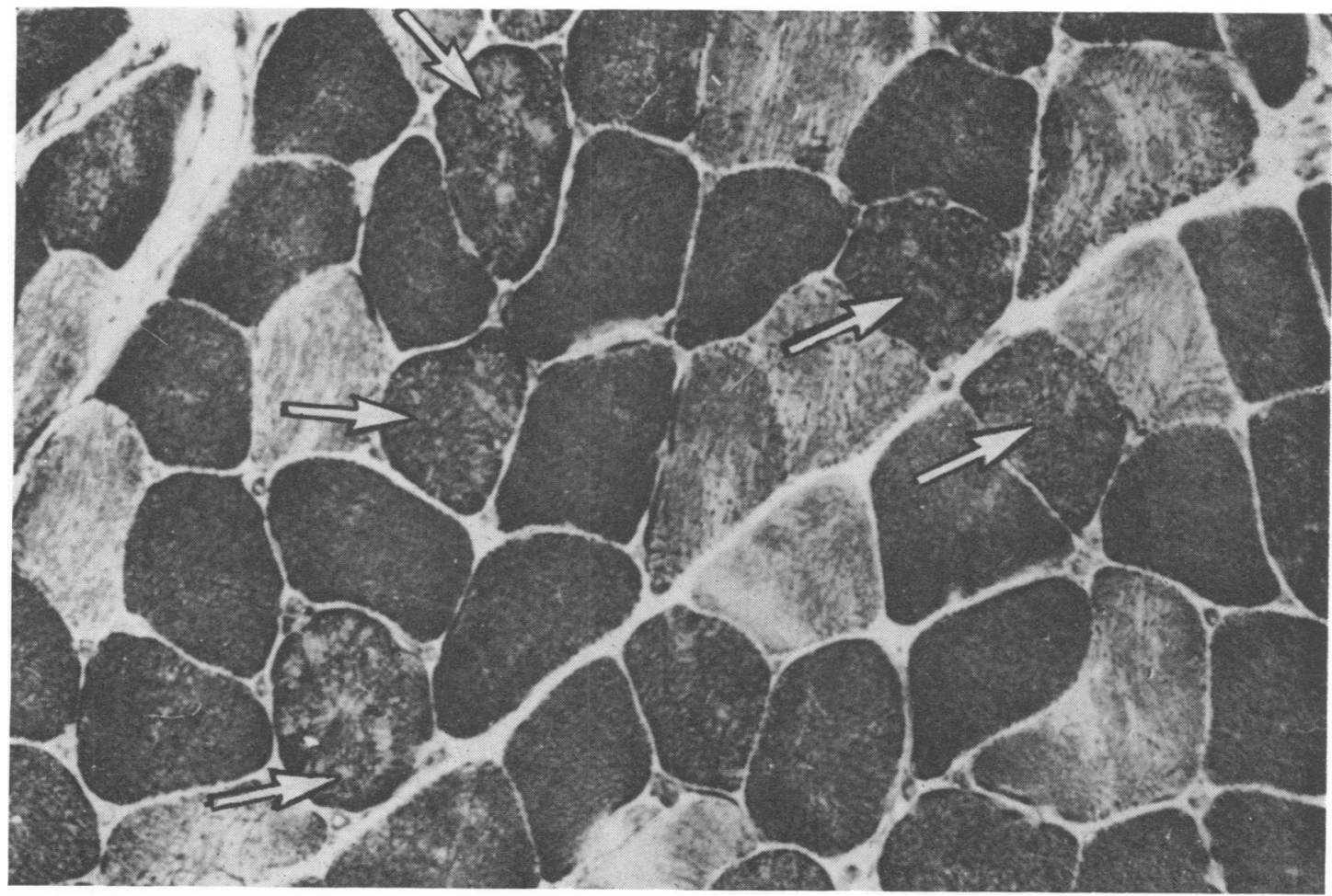

FIG. 1. Transverse section of deltoid muscle from case 4. Abnormal type 1 fibres (arrowed) are present within a normal mozaic of type 1 (dark) and type 2 (light) fibres. Reduced diphosphopyridine nucleotide diaphorase (DPNHD), $\times 500$. 


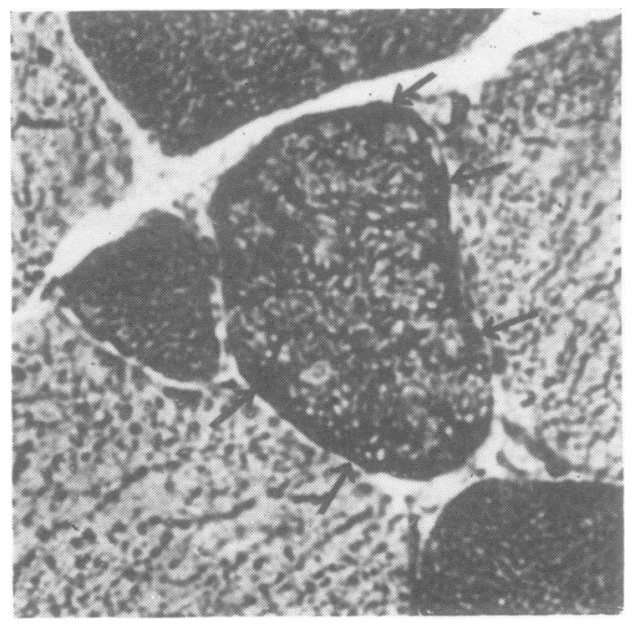

FIG. 2

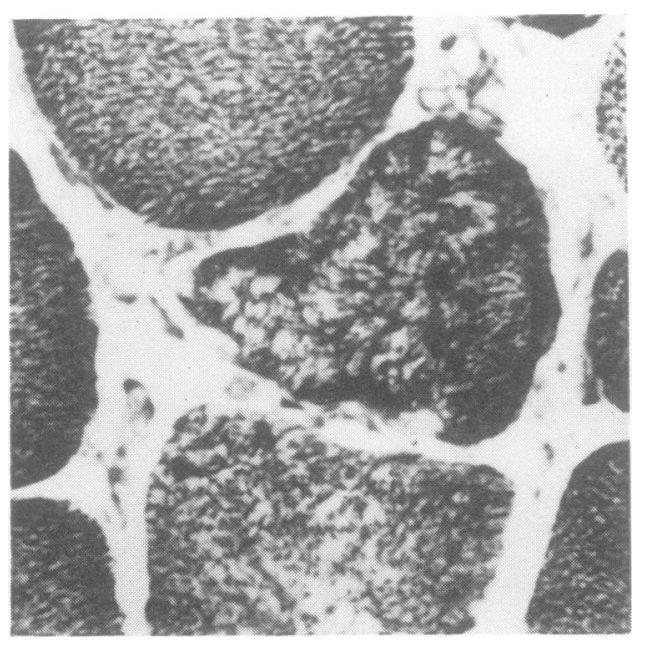

FIG. 3

FIGS. 2-4. Transverse sections of deltoid muscles from cases 1, 3, and 5. The small angular type 1 fibres have heavy subsarcolemmal enzyme activity (arrowed in Fig. 2) and coarse intermyofibrillar networks. DPNH-D, $\times 1,000$.

2. Fibres of mean diameter or above with the great proportion of the intermyofibrillar network of normal thickness. The network was, however, grossly disturbed, large areas being completely devoid of enzyme activity. There were a few subsarcolemmal enzyme masses and also aggregations of intense activity scattered throughout the fibre (Figs. 5, 6, 7).

All the definite and probable carriers were found

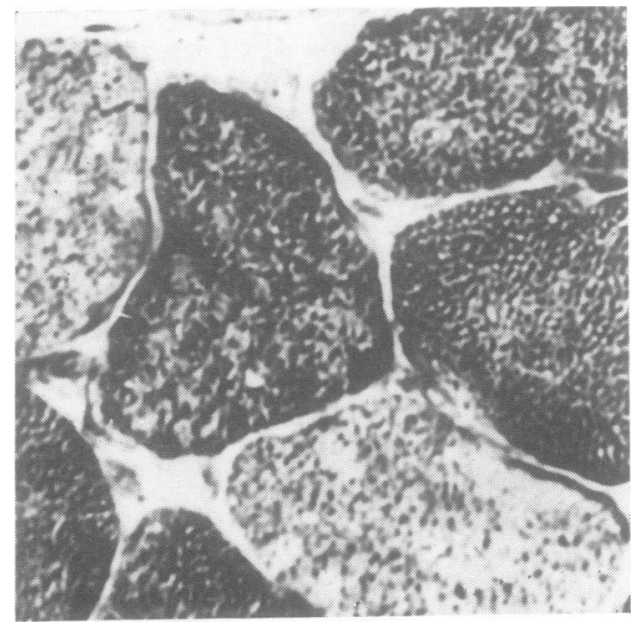

FIG. 4

to have more abnormal fibres than the normal group (cases 12-17). The possible carriers all had percentages of abnormal fibres above those of $\omega$ normals with the exception of case 9, which w well within the normal range.

\section{DISCUSSION}

The abnormalities observed in both the normal and $ᄃ$ carrier muscle fibres were very similar, although the more severe atrophic changes were seen only in the carrier muscle. The abnormally heavy deposits $\overrightarrow{G i}^{*} v$ oxidative enzyme activity probably represent. increase in number, or abnormality of the mitochondria, since reduced diphosphopyridine nucleotide diaphorase is known to be located in themo (Novikoff, Shin, and Drucker, 1961). This view is

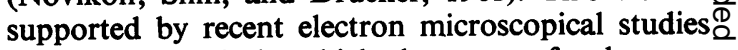
of carrier muscle in which there were focal aggre $-\overrightarrow{\vec{A}}$ gations of abnormally large numbers of mito- $\frac{3}{3}$ chondria, some showing increase in size (Milhorat, Shafiq, and Goldstone, 1966; Roy and Dubowitz, 1970). In one of these studies (Roy and Dubowitz, 1970) the histochemical stains in one case showed similar changes to those found by us, some of the type 1 fibres having irregularly distributed masses of 3 . oxidative enzyme activity attributed to the presence of mitochondrial aggregations. The electron micro- $\frac{3}{3}$ scopical studies have also revealed areas of focal ${ }_{0}$ degeneration with loss of myofibrils and destruction of the intermyofibrillar network seen in all the histochemically abnormal fibres. There seems little doubt that the observed histochemical changes in the $N$ muscle fibres are the result of a degenerative process, $N$ active in both normal and carrier muscle but moreN extensive and severe in the latter. The spectrum of 


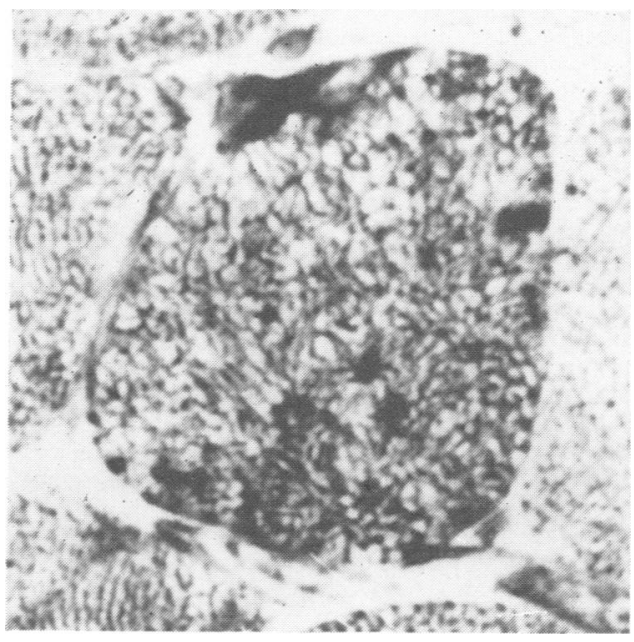

FIG. 5

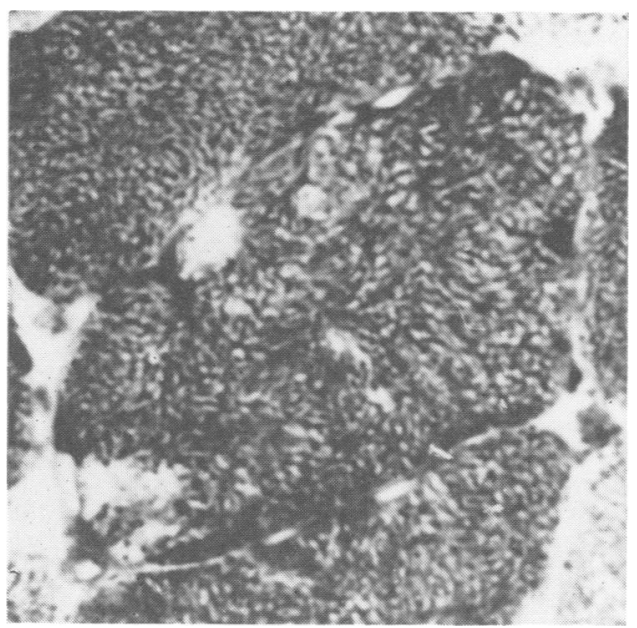

FIG. 6

FIGS. 5-7. Transverse sections of deltoid muscles from cases 7,8 , and 10. The type 1 fibres have only occasional subsarcolemmal enzyme masses and there are areas devoid of enzyme activity. DPNH-D, $\times 1,000$.

changes noted in the abnormal fibres in this study and in previous electron microscopical studies suggest that the degenerating fibre first increases in size with splitting and separation of myofibrils associated with disruption of the intermyofibrillar network and subsequently atrophies with severe loss of myofibrils and clumping of the intermyofibrillar network. The fact that the histochemical changes are mostly confined to the type 1 fibres is very difficult to explain, though it has been suggested

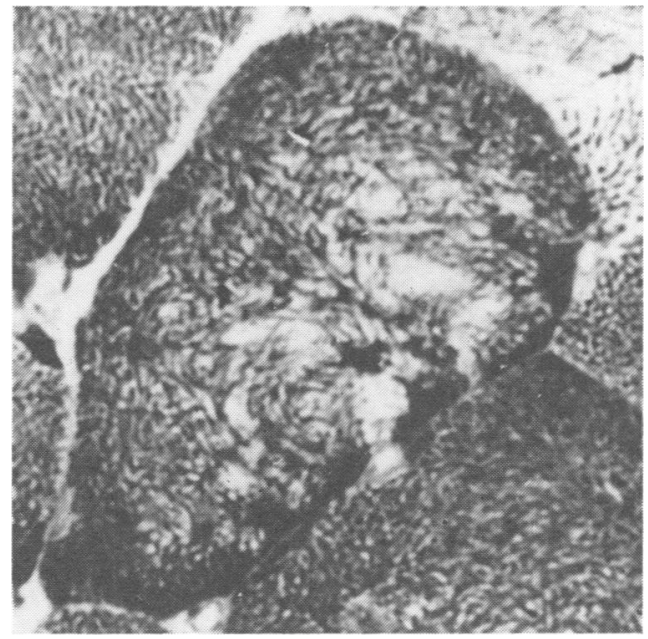

FIG. 7

that selective involvement of fibre types in some myopathies is due to the metabolic and structural difference between the two fibre types as demonstrated histochemically (Engel, 1965, 1970). Although the muscle from the definite carriers showed the most severe atrophic changes in type 1 fibres, they did not have the greatest percentage of abnormal fibres, these being found in the younger females in the group of possible carriers. The presence of large numbers of abnormal fibres in muscle from possible carriers was also noted in a previous study (Roy and Dubowitz, 1970). The cases with the highest numbers of affected fibres (cases 4 and 7) had the lowest levels of creatine phosphokinase (CPK), whereas case 8 , with a small percentage of abnormal fibres, had a high CPK. The cases with the most severe changes (cases 2 and 3 ) did, however, have the highest CPK values, but case 8 with a high CPK, had only slight fibre abnormalities. Similar inconsistencies were found in previous studies (Dubowitz, 1963b; Roy and Dubowitz, 1970).

The percentage of abnormal type 1 fibres in case 16 was higher than that of the other normal muscles, a finding which could be explained by the presence of an abnormally large number of collateral sprouts of the terminal nerve fibres in methylene blue preparations (Evans, Haynes, Morris, and Woolf, 1971) from this case. The possibility exists that there is a difference in abnormal type 1 fibre percentages in normal muscle from different sexes, a fact which we have not been able to investigate owing to a lack of normal female muscle. It seems unlikely, however, that this would explain the large differences seen between the male controls and the dystrophic carriers, particularly as one of these 
(case 9) has a percentage of abnormal fibres well within the control range.

On the basis of this study, with a rather limited amount of normal material, all the carriers and potential carriers, with the exception of case 9, could be classed as having abnormally large numbers of degenerating muscle fibres. Two cases (cases 4 and 7) would appear to be unequivocally abnormal, even though other conventional tests for the carrier state were completely normal. Histochemistry could, therefore, be a useful adjunct to the existing tests for the carrier state in Duchenne muscular dystrophy, having the advantage of detecting the more subtle abnormalities in muscle fibres not readily demonstrated by conventional histological techniques.

My thanks are due to Mr. R. A. Westhead for the creatine kinase estimations and to the surgeons and staff at the Royal Orthopaedic Hospital, Northfield, for the muscle from the orthopaedic cases. The untiring efforts of the late Dr. A. L. Woolf made most of the carrier muscle available to us. This work is supported by a grant from the Muscular Dystrophy Group of Great Britain.

\section{REFERENCES}

Adams, R. D. (1969). Pathological reactions of the skeletal muscle fibre in man. In Disorders of Voluntary Muscle, 2nd edition, pp. 150-151. Edited by J. N. Walton. Churchill.

Burstone, M. S. (1957). Polyvinyl pyrrolidone as a mounting medium for stains for fat and azo-dye procedures. Amer. J. clin. Path., 28, 429430.

Coërs, C., and Woolf, A. L. (1959). The Innervation of Muscle: A biopsy study, pp. 1-7. Blackwell: Oxford.

Dubowitz, V. (1963a). Myopathic changes in a muscular dystrophy carrier. J. Neurol. Neurosurg. Psychiat., 26, 322-325.

Dubowitz, V. (1963b). Myopathic changes in muscular dystrophy carriers. Proc. roy. Soc. Med., 56, 810-812.

Emery, A. E. H. (1963). Clinical manifestations in two carriers of Duchenne muscular dystrophy. Lancet, 1, 1126-1128.

Emery, A. E. H. (1965a). Carrier detection in sex-linked muscular dystrophy. J. Génét. hum., 14, 318-329.

Emery, A. E. H. (1965b). Muscle histology in carriers of Duchenne muscular dystrophy. J. med. Genet., 2, 1-7.

Engel, W. K. (1965). Diseases of the neuromuscular junction and muscle. In Neurohistochemistry pp. 666-668. Edited by C. W. M. Adams. Elsevier: Amsterdam.

Engel W. K. (1970). Selective and non-selective susceptibility of muscle fiber types. A new approach to human neuromuscular diseases. Arch. Neurol. (Chic.), 22, 97-117.
Engel, W. K., and Cunningham, G. G. (1970). Alkaline phosphatase-positive abnormal muscle fibers of humans. J. Histochem. Cytochem., 18, 55-57.

Evans, R. H., Haynes, J., Morris, C. J., and Woolf, A. L. (1971). The in-vitro staining of intramuscular nerve endings. J. Neurol. Neurosurg. Psychiat. (In press).

Hughes, B. P. (1962). A method for the estimation of serum creatine kinase and its use in comparing creatine kinase $\underbrace{\mathscr{N}}$ and aldolase activity in normal and pathological sera. Clin. Chim. Acta, 7, 597-603.

Ionasescu, V., Vuia, O., Luca, N., Popa, P., Anutei, V., and Anutei, E. (1968). Biochemical and histopathological $<$ studies of the carrier state in Duchenne's muscular dystrophy. Confin. neurol. (Basel), 30, 5-6, 289-300.

Milhorat, A. T., Shafiq, S. A., and Goldstone, L. (1966). $\overrightarrow{0}$ Changes in muscle structure in dystrophic patients, carriers and normal siblings seen by electron microscopy; correlation with levels of serum creatinephosphokinase (PK). Ann N.Y. Acad. Sci., 138, 246-292.

Novikoff, A. B., Shin, W.-Y., and Drucker, J. (1961). Mitochondrial localization of oxidative enzymes: staining results with two tetrazolium salts. J. biophys. biochem. $\vec{\circ}$ Cytol., 9, 47-61.

Pearce, G. W., Pearce, J. M. S., and Walton, J. N. (1966). The Duchenne type muscular dystrophy: histopathological studies of the carrier state. Brain, 89, 109-120.

Pearce, J. M. S., Pennington, R. J. T., and Walton, J. N. (1964). Serum enzyme studies in muscle disease. III. Serum creatine kinase activity in relatives of patients with the Duchenne type of muscular dystrophy. J. Neurop $\omega$ Neurosurg. Psychiat., 27, 181-185.

Radu, H., Migea, S., Török, Z., Bordeianu, L., and Radu, (1968). Carrier detection in $x$-linked Duchenne-ty muscular dystrophy. A pluridimensional investigation J. neurol. Sci., 6, 289-300.

Roy, S., and Dubowitz, V. (1970). Carrier detection û Duchenne muscular dystrophy. A comparative study of electron microscopy, light microscopy and serum enzym J. neurol. Sci., 11, 65-79.

Scarpelli, D. G., Hess, R., and Pearse, A. G. E. (1958). The cytochemical localization of oxidative enzymes. 1. Diphosphopyridine nucleotide diaphorase and triphosphopyridine nucleotide diaphorase.J. biophys. biochem. Cytol., 4, 747-751.

Siegel, A. L., and Cohen, P. S. (1966). An automated deter- $\bar{O}$ mination of serum creatine phosphokinase. Clin. Chem. ̊ำ (Abstract), 12, 532.

Smith, H. L., Amick, L. D., and Johnson, W. W. (1966). Detection of subclinical and carrier states in Duchenne $\overline{\bar{O}}$ muscular dystrophy. J. Pediat., 69, 67-79.

Stephens, J., and Lewin, E. (1965). Serum enzyme variations and histological abnormalities in the carrier state in Duchenne dystrophy. J. Neurol. Neurosurg. Psychiat. 28, 104-108.

Thompson, M. W., Murphy, E. G., and McAlpine, P. J. (1967). An assessment of the creatine kinase test in the detection of carriers of Duchenne muscular dystrophy. J. Pediat., 71, 82-93. 